\title{
O PROTAGONISMO JUVENIL NA CONSTRUÇÃO DO SISTEMA ÚNICO DE SAÚDE: UMA INTERVENÇÃO EDUCATIVA ON-LINE
}

\section{Ana Suelen Pedroza Cavalcane}

Mestre em Saúde da Família pelo Programa de Pós-Graduação em Saúde da Família da Universidade Federal do Ceará (UFC). Doutoranda em Saúde Coletiva pelo Programa de Pós-Graduação em Saúde Coletiva da Universidade Estadual do Ceará (UECE), Brasil.

\section{Maristela Inês Osawa Vasconcelos}

Doutora em Enfermagem pela Universidade Federal do Ceará (UFC). Docente do curso de Enfermagem da Universidade Estadual Vale do Acaraú (UVA). Pró-reitora de Pesquisa e Pós-Graduação da UVA, Brasil.

\section{Andrea Carvalho Araújo Moreira}

Doutora em Enfermagem pela Universidade Federal do Ceará (UFC). Docente e Coordenadora do curso de Enfermagem da Universidade Estadual Vale do Acaraú (UVA), Brasil.

\section{Izabelle Mont'Alverne N. Albuquerque}

Doutora em Enfermagem pela Universidade Federal do Ceará (UFC). Docente do curso de Enfermagem da Universidade Estadual Vale do Acaraú (UVA). Vice-reitora da UVA, Brasil.

\section{Marcos Aguiar Ribeiro}

Mestre em Saúde da Família pelo Programa de Pós-Graduação em Saúde da Família da Universidade Federal do Ceará (UFC). Doutorando em Enfermagem pelo Programa de Pós-Graduação em Enfermagem da Universidade Federal de São Paulo (UNIFESP). Auditor do Departamento Municipal de Auditoria do SUS (DEMASUS) da Secretaria Municipal de Saúde de So$\mathrm{bral} / \mathrm{CE}$, Brasil

\section{Quiteria Larissa Teodoro Farias}

Enfermeira graduada pela Universidade Estadual Vale do Acaraú (UVA). Mestranda em Saúde da Família pelo Programa de Pós-Graduação em Saúde da Família da Universidade Federal do Ceará (UFC), Brasil.
RESUMO: O objetivo deste estudo foi verificar os efeitos de uma intervenção educativa on-line sobre protagonismo juvenil no SUS. Trata-se de pesquisa-intervenção de abordagem quali-quantitativa desenvolvida com 22 adolescentes de uma escola pública profissionalizante, no período de outubro a dezembro de 2015. Para coleta de informações e avaliação da intervenção optou-se pela aplicação de um questionário antes e após a mesma. Os dados foram analisados por meio da estatística descritiva simples. A intervenção foi promovida a partir do desenvolvimento de um curso on-line, com três unidades de aprendizagem: Saúde - antes e depois do SUS; Participação em Saúde e Protagonismo Juvenil; e Serviços de Saúde. A avaliação da intervenção indica que a mesma potencializou e acrescentou conhecimentos aos adolescentes. Mostra-se, portanto, a relevância da formulação de estratégias promotoras da participação dos adolescentes no SUS e como estas contribuem para a construção e consolidação do mesmo.

PALAVRAS-CHAVE: Tecnologia da Informação; Participação da Comunidade Promoção da Saúde.

\section{JUVENILE AGENCY IN THE CONSTRUCTION OF THE BRAZILIAN HEALTH SERVICE: AN ONLINE EDUCATION- AL INTERVENTION}

\begin{abstract}
The effects of online education intervention on juvenile agency in the Brazilian health Service are analyzed. Current qualitative-quantitative research intervention was developed with 22 adolescents from a government-run profession school, during October-December 2015. A questionnaire prior to and posterior to the intervention was conducted for data collection and evaluation of the intervention. Data were analyzed by simple descriptive statistics. Intervention was enhanced through the development of an online course featuring three learning units: Health - prior and posterior to the NHS; Participation and Health and Juvenile Agency; Health Services. Assessment of intervention shows that it empowers and increases knowledge in young people. It reveals the relevance of strategies that promote the participation of adolescents in the NHS and the manner they contribute towards its construction and consolidation.
\end{abstract}

KEY WORDS: Information Technology; Community participation; Health promotion. 


\section{INTRODUÇÃO}

A população brasileira é bastante heterogênea e tem passado por profundas mudanças, sejam elas demográficas, econômicas ou sociais ${ }^{1}$. A geração de adolescentes e jovens que correspondia a $27,3 \%$ da população em 2004, passou a 24,1\% em 2014, e a tendência de diminuição deste grupo populacional é apontada pela Projeção da População por Sexo e Idade atingindo 21,0\%, em 2030, e $15,3 \%$, em $2060^{2}$.

A Política Nacional de Atenção à Saúde de Adolescentes e Jovens, criada em 2007 pelo Ministério da Saúde (MS) com o objetivo de incorporar a atenção à saúde destes grupos às redes de atenção do Sistema Único de Saúde (SUS), define o protagonismo juvenil como a participação ativa dos jovens nos processos sociais que envolvem sua vida. Trata-se de um processo pedagógico que incentiva um relacionamento democrático entre jovens e adultos, baseado na solidariedade ${ }^{3}$.

Em 2013, essa população, a partir do Estatuto da Juventude, teve consolidados seus direitos quanto à cidadania, à participação social e política e à representação juvenil, que consiste no incentivo à criação de conselhos de juventude de forma a torná-los seres críticos e políticos dentro do processo de aprender a ser e aprender a aprender. Todo esse movimento envolve a articulação de diversos equipamentos sociais voltados à saúde e à educação, por meio de um trabalho intersetorial ${ }^{4}$.

Neste sentido, a Política Nacional de Promoção da Saúde enfatiza a necessidade de participação e propõe o fortalecimento do protagonismo dos cidadãos no planejamento, gestão, e acompanhamento de políticas públicas, de forma que a população participe das decisões de saúde dos seus municípios, Estados e país 5 .

A escola atua, portanto, como um desses espaços de formação para a cidadania ${ }^{6}$, à medida que é diretamente responsável pela formação crítica-reflexiva necessária para que o adolescente se perceba como um protagonista. Logo, utilizando-se da intersetorialidade a escola se faz como um espaço propício para o desenvolvimento do protagonismo juvenil no SUS.

Para tal, se faz importante a utilização de múltiplos meios que alcancem o público em questão. Sabe-se que o setor saúde carece de novas tecnologias que pos- sam ampliar o conhecimento e empoderar a comunidade com informações de saúde ${ }^{7}$. Dessa forma, torna-se necessário pensar essa intermediação pelo uso das Tecnologias de Informação e Comunicação (TIC), tendo em vista que estas são apontadas como facilitadoras do processo de ensino-aprendizagem e motivadora de jovens, além de possibilitar a democratização do acesso à informação ${ }^{8}$.

Diante disso, o modelo tradicional de ensino-aprendizagem tem sido transposto para a educação que utiliza essas novas TIC, sendo necessário considerar as especificidades desses novos Ambientes Virtuais de Aprendizagem (AVA) ${ }^{8}$. Assim, a utilização do AVA cumpre a função de apoiar o ensino presencial, na tentativa de amenizar possíveis lacunas existentes.

Este estudo visa, portanto, fomentar a inovação nas ações da saúde integral dos adolescentes por meio de uma tecnologia de informação e interação virtual com a utilização de um AVA como ferramenta facilitadora do processo de ensino-aprendizagem de disseminação de conhecimentos acerca da saúde.

Logo, a fim de aumentar e estimular a participação dos adolescentes, busca-se uma nova metodologia que propicie um espaço de reflexão sobre atenção integral da saúde, com o intuito de proporcionar a co-responsabilização do cuidado e também a autonomia desses sujeitos no fazer saúde.

Nessa perspectiva, o objetivo deste estudo é verificar os efeitos de uma intervenção educativa on-line sobre protagonismo juvenil no SUS com adolescentes escolares

\section{METODOLOGIA}

Trata-se de uma pesquisa de intervenção pedagógica, de abordagem qualitativa e quantitativa. Os participantes do estudo foram estudantes adolescentes do curso de informática de uma escola pública profissionalizante da cidade de Sobral, localizada no Estado do Ceará, Brasil, no mês de novembro de 2015. Foram convidados a participar do estudo 35 adolescentes. No entanto, 32 aceitaram e apenas 22 concluíram o curso, participando da intervenção e de sua avaliação.

O estudo foi realizado no período de outubro 
a dezembro de 2015 e foi dividido em duas fases, sendo estas: o planejamento e a implementação da intervenção e na sua avaliação. A intervenção constituiu-se na construção e implementação de um curso on-line disponibilizado na plataforma moodle intitulado "\#PARTICIPADOLEC".

O curso teve duração de 16 horas e foi organizado em atividades presenciais e virtuais. Os encontros presenciais tiveram uma carga horária de 2 horas cada e os virtuais corresponderam a uma carga horária de 4 horas cada. Os conteúdos propostos para este curso foram compostos por três unidades de aprendizagem, a saber: 1) Saúde: antes e depois do SUS; 2) Participação em Saúde e Protagonismo Juvenil; e 3) Serviços de Saúde.

As temáticas supracitadas foram abordadas a partir da leitura de textos que foram escritos de forma a se aproximar os adolescentes do conteúdo proposto. Em seguida os adolescentes participavam de chats ou fóruns para que pudessem conversar e trocar experiências sobre cada temática abordada. O curso disponibilizou ainda vídeos e outros textos para que os mesmos tivessem acesso.

Optou-se primeiro por apresentá-los à construção do nosso sistema público de saúde de forma a realizar um resgate histórico; na segunda unidade didática foi enfocada a participação juvenil para que eles se percebessem como importantes na participação nas políticas públicas; e por último foram abordados os serviços e as redes de atenção à saúde, de modo que eles pudessem conhecer todos os dispositivos que podem lhe dar apoio para tal.

Para o desenvolvimento do estudo foi realizado o contato inicial com a direção da escola para apresentação da proposta e solicitação da aquiescência. Em seguida, o convite foi realizado aos adolescentes do $1^{\circ}$ ano do ensino médio que estavam matriculados no curso de informática e solicitada permissão por escrito aos seus pais. Posteriormente, ocorreu a intervenção propriamente dita, em 03 encontros virtuais e 02 presenciais. No primeiro encontro presencial houve a capacitação sobre 0 uso do AVA para realização do curso.

Para coleta de informações e avaliação da intervenção optou-se pela aplicação de um questionário antes e após a mesma. Este questionário continha três domí- nios: Conhecimento, Atitude e Prática (CAP), baseado no inquérito $\mathrm{CAP}$, ao qual diz respeito a um conjunto de questões que visam mensurar o conhecimento de uma população frente a determinada temática, bem como o que ela pensa e como ela atua com relação a esta, podendo assim identificar caminhos para intervenções mais eficazes?

Foram considerados como: Conhecimento Adequado - quando o participante tiver algum conhecimento sobre o SUS ser uma conquista social e entender o que é o protagonismo juvenil; Conhecimento Inadequado quando o participante não tem conhecimento sobre o SUS e sobre o protagonismo juvenil; Atitude Adequada - quando o participante reconhece, a ele e a qualquer outro brasileiro, o papel de protagonista no SUS; Atitude Inadequada - quando o participante não reconhece a participação no SUS; Prática Adequada - quando o participante tem interesse em participar e identifica as formas de participação no SUS; Prática Inadequada - quando o participante não tem interesse em participar e não identifica as formas de participação no SUS.

Posteriormente, os dados obtidos pela aplicação do questionário foram tabulados no Programa Epiinfo ${ }^{\circledR}$ versão 7.1.2.0 e analisados pela estatística descritiva simples. Ressalta-se que foi aplicado um teste piloto do questionário antes de ser entregue aos adolescentes deste estudo. A versão piloto foi entregue a 30 adolescentes que não participaram do estudo para que fosse validado. Houve alteração somente de termos apresentados nas questões que os adolescentes não sabiam os significados. Assim, foram substituídos por sinônimos sugeridos pelos próprios adolescentes, após a explicação do que o termo significava.

As informações qualitativas foram as atividades realizadas pelos adolescentes ao participarem dos fóruns e chats proporcionadas pelo curso, as quais foram lidas na íntegra e analisadas a partir da literatura existente.

O estudo está em consonância com a Resolução 466/12 que assegura os direitos dos participantes do estudo e protege sob a ótica do indivíduo e das coletividades. O estudo obteve parecer favorável do Comitê de Ética em Pesquisas com Seres Humanos da Universidade Estadual Vale do Acaraú, sob o número 1.237.144. 


\section{RESULTADOS}

\section{PLANEJAMENTO DA INTERVENÇÃO}

Na elaboração do plano pedagógico do "ParticipAdolec", foi realizado um aprofundamento teórico na literatura disponível no meio eletrônico, bem como selecionados textos e conteúdos gráficos: imagens ilustrativas e vídeos relacionados com participação em saúde. Cada material foi analisado individualmente de modo a verificar sua adequação, por membros de um grupo de pesquisa, contando ainda com o apoio de um expert de informática, que auxiliou na compactação de todo o material de mídia e design da logomarca, resultando na versão final.

Após o material ser analisado e selecionado, elaborou-se um roteiro do conteúdo educacional para as três unidades de aprendizagem mencionadas anteriormente, com os seguintes objetivos de aprendizagem: Conhecer a assistência à saúde antes da implementação do SUS; Conhecer o SUS e os diversos serviços oferecidos pelo mesmo; Conhecer as formas de participação em saúde; Conhecer experiências de protagonismo juvenil na saúde; e Promover espaços de discussão e troca de conhecimento com os adolescentes.

Assim, o "ParticipAdolec" foi elaborado com uma proposta metodológica interativa para fomentar atitudes dialógicas e participativas. Os usuários do moodle tinham um espaço para fazer o registro de suas percepções sobre os conteúdos abordados, com um espaço específico para o adolescente e outro para o facilitador. Também houve espaços destinados para a integração entre todos os usuários, de modo que eles pudessem trocar experiências, dúvidas e conhecimentos. Foram disponibilizados ainda materiais na íntegra que serviram como textos de apoio.

\section{IMPLEMENTAÇÃO DA INTERVENÇÃO}

O curso \#PARTICIPADOLEC, Figura 1, foi disponibilizado mediante link na Internet e o seu acesso ocorreu por meio de um cadastro realizado pelo próprio adolescente, com login e senha, na página inicial do moodle. O cadastro foi solicitado ao administrador, e apenas após a aprovação é que o participante tinha livre acesso. Além disso, o curso foi cadastrado na Pró-Reitoria de Extensão e Cultura da Universidade Estadual Vale do Acaraú (UVA) para que os concludentes recebessem certificação.

Foram utilizados os dois laboratórios de informática das dependências da escola. Neste sentido, os estudantes foram divididos para que cada um permanecesse em um computador da escola para realizar as atividades, com a supervisão do pesquisador e de integrantes de seu grupo de pesquisa. Além disso, os estudantes que tinham acesso à Internet no domicílio foram incentivados a acessar os conteúdos do curso sempre que tivessem interesse.

O primeiro encontro realizado, após a entrega dos Termos de Assentimento e Consentimento dos responsáveis, foi presencial para apresentar o curso aos adolescentes, mostrar as funcionalidades que foram ofertadas por meio do moodle, efetuar o cadastro na plataforma $\mathrm{e}$ responder ao questionário CAP.

Os três encontros subsequentes foram realizados no AVA, onde os adolescentes tiveram a oportunidade de desenvolver as atividades. No primeiro momento, eles liam os textos que foram sistematizados especialmente para este curso, com o auxílio das literaturas selecionadas e assistiam aos vídeos, mediante link disponibilizado. Após a leitura, os adolescentes realizavam uma atividade para expressar o que haviam entendido da temática da aula proposta. As atividades eram expressas por meio de textos, poesias e desenhos evidenciando tanto o conhecimento prévio, como o adquirido com o curso, das quais eram enviadas para a plataforma, em que o facilitador tinha acesso para conceder suas considerações e trocar experiências com os mesmos, por meio de mensagens.

Além disso, tiveram a oportunidade de discutir em chats com todos os participantes do curso e com convidados dos serviços de saúde do município que residem, de modo a conhecer mais sobre a realidade local em que estão inseridos. 


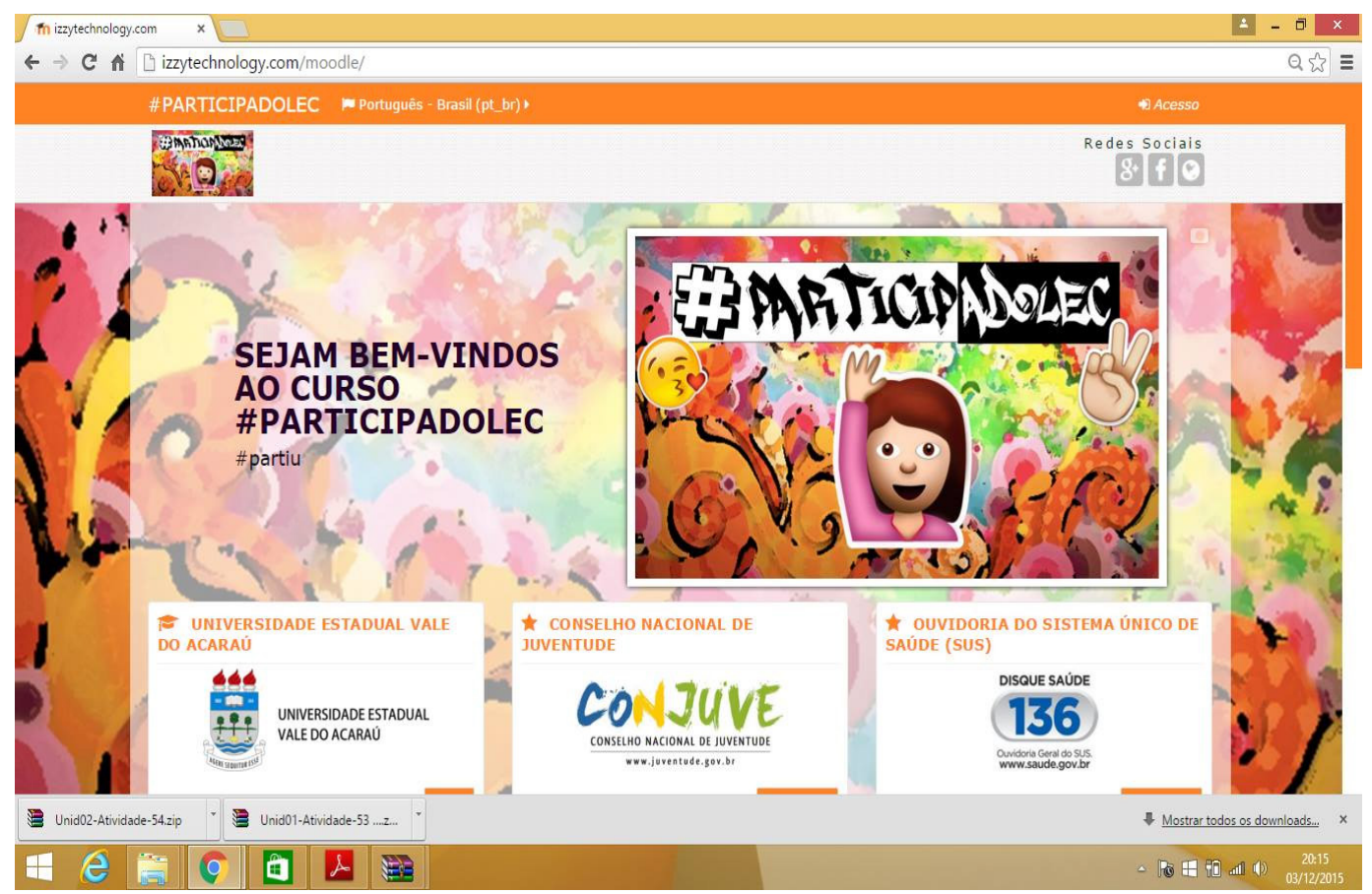

Figura 1. Página inicial do Ambiente Virtual de Aprendizagem do curso \#PARTICIPADOLEC. Sobral, Ceará, Brasil, 2018

\section{AVALIAÇÃO DA INTERVENÇÃO}

Nesta etapa, aplicou-se um questionário que permitiu avaliar a intervenção, em que pôde-se extrair: o perfil dos adolescentes, os conhecimentos, as atitudes e as práticas, como pode ser verificado nos quadros 1,2 , 3 e 4 .

A idade dos participantes deste estudo variou de 16 a 18 anos, sendo a renda familiar predominante de 1 a 2 salários mínimos. A maioria (75\%) possui computadores em casa, com acesso à Internet, em contrapartida, este mesmo quantitativo não havia participado de nenhum curso à distância, como mostra o Quadro 1.

Verificou-se que após a intervenção houve um acréscimo de respostas consideradas adequadas em relação ao conhecimento, uma vez que mais participantes reconheceram o Sistema Único de Saúde como um sistema que garante o direito à saúde de qualidade para todos os cidadãos, resultado de uma conquista social, como pode ser verificado no Quadro 2.

Além disso, identificou-se que os participantes tinham um conhecimento adequado sobre o conceito de protagonismo juvenil, por considerarem que o mesmo ocorre por meio de uma participação ativa dos adolescentes.
Em relação às atitudes os adolescentes reconheceram ainda mais após a intervenção que todos os cidadãos podem participar da construção do SUS e que os mesmos são fundamentais nesse processo, como pode ser observado no Quadro 3.

No que se refere às práticas, após a intervenção, grande maioria se reconheceu como protagonistas e manifestaram o interesse em participar de atividades que contribuam de alguma maneira para a saúde, uma vez que puderam conhecer mais sobre este conceito e sobre as formas de protagonizar, conforme explanado no Quadro 4.

Passaram ainda a identificar mais formas de participação em saúde, uma vez que mais deles assinalaram diferentes opções quando indagados sobre como participar da melhoria da saúde. 
Quadro 1. Perfil dos adolescentes escolares que participaram da intervenção. Sobral, nov. 2015

\begin{tabular}{|c|c|c|}
\hline Idade & $\mathbf{N}$ & $\%$ \\
\hline 16 anos & 14 & $63,64 \%$ \\
\hline 17 anos & 7 & $31,82 \%$ \\
\hline 18 anos & 1 & $04,55 \%$ \\
\hline Renda Familiar & $\mathbf{N}$ & $\%$ \\
\hline 1 a 2 salários mínimos & 16 & $72,73 \%$ \\
\hline 3 a 4 salários mínimos & 2 & $09,09 \%$ \\
\hline Mais de 4 salários mínimos & 1 & $04,55 \%$ \\
\hline Menos de 1 salário mínimo & 3 & $13,64 \%$ \\
\hline Computador em casa & $\mathbf{n}$ & $\%$ \\
\hline Sim & 17 & $77,27 \%$ \\
\hline Não & 5 & $22,73 \%$ \\
\hline Acesso à Internet & $\mathbf{n}$ & $\%$ \\
\hline Sim & 21 & $95,45 \%$ \\
\hline Não & 1 & $04,55 \%$ \\
\hline Local de Acesso à Internet & $\mathbf{N}$ & $\%$ \\
\hline Em casa & 16 & $72,73 \%$ \\
\hline Na escola & 8 & $36,36 \%$ \\
\hline $\mathrm{Na}$ casa de amigos ou parentes & 4 & $18,18 \%$ \\
\hline Em lanbouse ou cyber & 1 & $04,55 \%$ \\
\hline Já fez curso à distância? & $\mathbf{N}$ & $\%$ \\
\hline Sim & 2 & $9,09 \%$ \\
\hline Não & 17 & $77,27 \%$ \\
\hline Não lembra & 3 & $13,64 \%$ \\
\hline
\end{tabular}

Fonte: Dados da pesquisa.

Quadro 2. Conhecimentos acerca da participação em saúde e protagonismo juvenil, antes e após a intervenção. Sobral, 2015

(Continua)

\begin{tabular}{|l|c|c|c|c|}
\hline \multicolumn{2}{|c|}{ CONHECIMENTO } & \multicolumn{2}{c|}{ Após a intervenção } \\
\hline Assinale as opções abaixo que você considera correta: & \multicolumn{2}{|c|}{ Antes da intervenção } & $\%$ & N \\
\hline $\begin{array}{l}\text { O sistema de saúde brasileiro denomina-se Sistema Único de Saú- } \\
\text { de e garante o direito à saúde de qualidade para todos os cidadãos } \\
\text { brasileiros. }\end{array}$ & 15 & $68,18 \%$ & 19 & $86,36 \%$ \\
\cline { 2 - 6 } $\begin{array}{l}\text { A população brasileira tem direito aos mais diversos serviços de saú- } \\
\text { de por causa de muitas lutas sociais. }\end{array}$ & 6 & $27,27 \%$ & 10 & $45,45 \%$ \\
\hline $\begin{array}{l}\text { Apenas os gestores e profissionais da saúde podem contribuir para a } \\
\text { melhoria da saúde da população. }\end{array}$ & 2 & $09,09 \%$ & 2 & $09,09 \%$ \\
\hline $\begin{array}{l}\text { Existem várias formas de participação social em saúde, dentre elas } \\
\text { encontram-se os conselhos de saúde, as ouvidorias e espaços de dis- } \\
\text { cussão sobre questões relacionadas à saúde. }\end{array}$ & 10 & $45,45 \%$ & 14 & $63,64 \%$ \\
\hline
\end{tabular}


(Conclusão)

\begin{tabular}{|l|c|c|c|c|}
\hline \multirow{2}{*}{$\begin{array}{l}\text { Marque a alternativa que considerar correta em relação ao pro- } \\
\text { tagonismo juvenil: }\end{array}$} & \multicolumn{2}{|c|}{ Antes da intervenção } & \multicolumn{2}{c|}{ Após a intervenção } \\
\hline $\begin{array}{l}\text { O adolescente é muito jovem e desse modo pode contribuir em } \\
\text { quase nada para a assegurar os seus direitos e para a resolução de } \\
\text { problemas dos locais onde vive. }\end{array}$ & $\mathbf{N}$ & $\%$ & N & 0 \\
\hline $\begin{array}{l}\text { A atuação de adolescentes, por meio de uma participação ativa em } \\
\text { questóes da própria adolescência, assim como com outras questões } \\
\text { sociais é o que caracteriza o protagonismo. }\end{array}$ & N & $\%$ & N & $\%$ \\
\hline O adolescente sempre precisa de um adulto para ser protagonista. & 1 & $95,45 \%$ & 21 & $95,45 \%$ \\
\hline
\end{tabular}

O direito à saúde é garantido por lei e foi uma conquista social onde teve a participação de vários brasileiros?

\begin{tabular}{|l|c|c|c|c|c|}
\hline \multirow{2}{*}{ Sim } & \multicolumn{2}{|c|}{ Antes da intervenção } & \multicolumn{3}{|c|}{ Antes da intervenção } \\
\cline { 2 - 6 } & $\mathbf{N}$ & $\%$ & \multicolumn{2}{|c|}{ N } & \multicolumn{2}{c|}{9} \\
\cline { 2 - 6 } & 5 & $22,73 \%$ & $20,91 \%$ & $0 \%$ \\
\hline Não sei & 0 & $0 \%$ & 0 & $09,09 \%$ \\
\hline
\end{tabular}

Fonte: Dados da pesquisa.

Quadro 3. Atitudes acerca da participação em saúde e protagonismo juvenil, antes e após uma intervenção. Sobral, 2015

\begin{tabular}{|c|c|c|c|c|c|c|}
\hline \multicolumn{7}{|c|}{ ATITUDE } \\
\hline $\begin{array}{l}\text { Leia as frases a seguir e marque com um X o grau de } \\
\text { concordância que você considera }\end{array}$ & \multicolumn{3}{|c|}{ Antes da intervenção } & \multicolumn{3}{|c|}{ Após a intervenção } \\
\hline & & $\mathbf{n}$ & $\%$ & & $\mathbf{n}$ & $\%$ \\
\hline \multirow{3}{*}{$\begin{array}{l}\text { O Sistema Único de Saúde (SUS) surgiu como resposta } \\
\text { à insatisfação e descontentamento existente em relação } \\
\text { aos direitos de cidadania, acesso, serviços e forma de } \\
\text { organização do sistema de saúde e é resultado de um } \\
\text { processo de mobilização e participação desenvolvido por } \\
\text { várias pessoas. }\end{array}$} & Concordo & 15 & $68,18 \%$ & Concordo & 18 & $81,82 \%$ \\
\hline & Discordo & 1 & $4,55 \%$ & Discordo & 2 & $9,09 \%$ \\
\hline & Não sei & 6 & $27,27 \%$ & Não sei & 2 & $9,09 \%$ \\
\hline \multirow{3}{*}{$\begin{array}{l}\text { Todos os cidadãos brasileiros podem participar de algu- } \\
\text { ma forma da construção do SUS. }\end{array}$} & Concordo & 12 & $54,55 \%$ & Concordo & 20 & $90,91 \%$ \\
\hline & Discordo & 3 & $13,64 \%$ & Discordo & 1 & $4,55 \%$ \\
\hline & Não sei & 7 & $31,82 \%$ & Não sei & 1 & $4,55 \%$ \\
\hline \multirow{3}{*}{$\begin{array}{l}\text { Os adolescentes são pessoas fundamentais na constru- } \\
\text { ção do SUS, por serem potenciais criativos e inovadores. }\end{array}$} & Concordo & 13 & $59,09 \%$ & Concordo & 21 & $95,45 \%$ \\
\hline & Discordo & 0 & $0 \%$ & Discordo & 0 & $0 \%$ \\
\hline & Não sei & 9 & $40,91 \%$ & Não sei & 1 & $4,55 \%$ \\
\hline
\end{tabular}

Fonte: Dados da pesquisa.

Quadro 4. Práticas acerca da participação em saúde e protagonismo juvenil, antes e após uma intervenção. Sobral. 2015

(Continua)

\begin{tabular}{|c|c|c|c|c|}
\hline \multicolumn{4}{|c|}{ PRÁTICA } \\
\hline Você se considera um protagonista na saúde? & \multicolumn{2}{|c|}{ Antes da intervenção } & \multicolumn{3}{c|}{ Após a intervenção } \\
\hline \multirow{2}{*}{$\operatorname{Sim}$} & $\mathrm{N}$ & $\%$ & $\mathrm{n}$ & $\%$ \\
\cline { 2 - 6 } & 13 & $59,09 \%$ & 18 & $81,82 \%$ \\
\cline { 2 - 6 } & 9 & $40,91 \%$ & 4 & $18,18 \%$ \\
\hline Não & \multicolumn{5}{|l}{} \\
\hline
\end{tabular}


(Conclusão)

\begin{tabular}{|c|c|c|c|c|}
\hline \multicolumn{5}{|l|}{ Marque a opção que justifica sua resposta anterior } \\
\hline \multirow{3}{*}{$\begin{array}{l}\text { Sim, pois estou sempre buscando informações sobre meus } \\
\text { direitos e deveres na saúde. Além disso, posso ser prota- } \\
\text { gonista quando troco experiências, construções de conhe- } \\
\text { cimentos, desenvolvo ações buscando o fortalecimento de } \\
\text { causas sociais e sensibilizo e mobilizo outras pessoas para } \\
\text { essas ou outras questões. }\end{array}$} & \multicolumn{2}{|c|}{ Antes da intervenção } & \multicolumn{2}{|c|}{ Após a intervenção } \\
\hline & $\mathrm{N}$ & $\%$ & $\mathrm{n}$ & $\%$ \\
\hline & 13 & $59,09 \%$ & 21 & $95,45 \%$ \\
\hline $\begin{array}{l}\text { Não. Eu acho que não posso fazer nada pela melhoria da } \\
\text { saúde. Sou apenas uma pessoa e nada posso fazer para } \\
\text { melhorá-la. }\end{array}$ & 9 & $40,91 \%$ & 1 & $04,55 \%$ \\
\hline \multicolumn{5}{|c|}{ Você tem interesse em participar de atividades que contribuam de alguma maneira para sua saúde e/ou da população? } \\
\hline \multirow{3}{*}{ ( } & \multicolumn{2}{|c|}{ Antes da intervenção } & \multicolumn{2}{|c|}{ Após a intervenção } \\
\hline & $\mathrm{N}$ & $\%$ & $\mathrm{n}$ & $\%$ \\
\hline & 18 & $81,82 \%$ & 21 & $95,45 \%$ \\
\hline Não & 4 & $18,18 \%$ & 1 & $04,55 \%$ \\
\hline \multicolumn{5}{|l|}{ Você participa da melhoria da saúde quando: } \\
\hline \multirow{3}{*}{$\begin{array}{l}\text { Faz reclamação, elogio ou sugestão na ouvidoria de algum } \\
\text { serviço de saúde ou na ouvidoria geral do SUS. }\end{array}$} & \multicolumn{2}{|c|}{ Antes da intervenção } & \multicolumn{2}{|c|}{ Após a intervenção } \\
\hline & $\mathrm{N}$ & $\%$ & $\mathrm{n}$ & $\%$ \\
\hline & 13 & $59,09 \%$ & 12 & $54,55 \%$ \\
\hline $\begin{array}{l}\text { Reflete sobre as condições de educação da população bra- } \\
\text { sileira e sugere melhorias. }\end{array}$ & 8 & $36,36 \%$ & 14 & $63,64 \%$ \\
\hline Procura se informar sobre seus direitos e deveres. & 9 & $40,91 \%$ & 12 & $54,55 \%$ \\
\hline Divulga informações para outras pessoas. & 8 & $36,36 \%$ & 14 & $63,64 \%$ \\
\hline Participa de reuniões do Conselho Municipal de Saúde. & 5 & $22,73 \%$ & 8 & $36,36 \%$ \\
\hline Participa de algum movimento social. & 3 & $13,64 \%$ & 8 & $36,36 \%$ \\
\hline
\end{tabular}

Fonte: Dados da pesquisa.

\section{DISCUSSÃO}

A partir da aplicação do inquérito CAP percebeu-se que os adolescentes conseguiram adquirir conhecimentos acerca do SUS e percebê-lo como uma conquista social. Conseguiram compreender ainda o que é protagonismo juvenil e como os mesmos podem estar exercendo o mesmo, despertando assim o interesse em estar procurando essas formas de inserção no controle social em seu município.

O fato da maioria dos adolescentes possuir computadores contribuiu para a realização do "ParticipAdolec", uma vez que permitiu momentos de discussões extras nos chats e o estudo dos materiais, mesmo que as principais atividades tenham sido desenvolvidas com a utilização dos computadores da escola.

Além disso, evidenciou que o "mundo virtual" faz parte do cotidiano e está bem próximo destes adolescentes e que embora tenham condições de renda baixas, o acesso à Internet tornou-se uma prioridade para as famílias o que vai de encontro a um estudo desenvolvido em 10 países, incluindo o Brasil, o qual mostra que mesmo os adolescentes de menor renda estão no mundo da Internet e utilizam de ferramentas digitais em seu cotidiano $^{10}$.

Esse mesmo estudo enfatiza ainda que $80 \%$ desses jovens estão entre 15 e 16 anos, o que se assemelha a este levando em consideração que grande parte da população em estudo se concentra na idade de 16 anos $(63,64 \%)^{10}$.

Acredita-se que os indivíduos só participam daquilo que lhes faz sentido e quando consideram que são fundamentais no processo de construção. Por isso, optou-se por apresentar o SUS e seus diversos serviços disponíveis, para depois expor as formas de participação e protagonismo em saúde.

Dessa forma, se reconhece que a educação é creditada a um processo de compartilhamento de experiências, elaborando conhecimentos por meio das relações que se estabelecem entre os diversos indivíduos. 
É por meio dessa interação que há possibilidades de construção, desconstrução e reconstrução da realidade, ressignificando as práticas e os saberes e possibilitando uma apropriação de um pensar, sentir e agir transformador em relação ao sistema ${ }^{11}$.

Pensando nisso, foram organizados espaços que possibilitaram a interação entre os participantes, a partir de uma abordagem dialógica. A mediação desta interação pode ser realizada por diversos métodos e técnicas que se utilizam de abordagens síncronas e assíncronas, nas quais acontecem respectivamente, em tempo real, ou seja, o facilitador e o estudante devem estar on-line, sendo assim proporcionados momentos de interação instantânea (chats); e independente da presença de ambos, de tempo ou de lugar, por meio dos registros deixados (fóruns de discussão) ${ }^{12}$.

As TIC estão presentes como ferramentas de estudos, pesquisa e como meio de comunicação, trazendo várias possibilidades a favor da aprendizagem, mas é importante salientar que o ambiente virtual condiciona, mas não determina a aprendizagem, pois esta dependerá de toda a comunicação pedagógica envolvida entre os sujeitos. A se tratar do moodle em especial, a literatura traz que o mesmo proporciona a possibilidade de construção do aprendizado, onde este é compartilhado continuamente, estimulando a criatividade dos envolvidos e abrindo assim um espaço para integrar diferentes teorias de aprendizagem e fortalecer o processo de ensinar e aprender ${ }^{13-14}$.

Toda essa metodologia contribuiu para os resultados adequados na avaliação da intervenção. À medida que possibilitou o conhecimento mais aprofundado dos adolescentes diante do sistema, fazendo-os se perceberem como partes do processo de construção contínua do SUS, por meio dos seus direitos e deveres e como podem estar os desenvolvendo em prol do sistema.

A partir das discussões acerca dos meios de participação popular, em relação à saúde, aos quais foram estabelecidos pela Lei 8.142/90 para promover espaços de escuta e, principalmente, aprimorar o processo de controle social, na tentativa de se defender os interesses coletivos $^{15}$. Torna-se fundamental a intensa utilização dos espaços institucionalizados de controle social, bem como dos espaços informais onde as pessoas podem estar se apropriando sobre seus direitos e deveres e compartilhar nos equipamentos sociais ao qual estão inseridos, neste caso tomando por exemplo a própria escola.

A possibilidade de discussão com os profissionais de saúde do município, por meio dos chats, viabilizou a associação da teoria à prática de sua realidade local, fortalecendo ainda mais essa aprendizagem significativa, ao perceber que não é uma realidade distante, mas algo que cotidianamente pode se expressar.

Na própria participação no grêmio estudantil são fomentados olhares mais profundos, críticos e responsáveis por problemas levantados na instituição escolar ${ }^{16}$, que acabam resultando em ações e comportamentos extramuros, gerando a inquietação para demais assuntos, inclusive de saúde.

Uma pesquisa-intervenção desenvolvida em Minas Gerais com adolescentes e jovens mostrou que é preciso desconstruir para construir, algumas concepções de discussão, saberes e de práticas em saúde. Assim como no presente estudo, foi possibilitada uma construção coletiva de outros sentidos para suas experiências singulares $^{17}$.

Dessa forma, ampliar esse caráter democrático e estimular a apropriação das decisões dos adolescentes, entendidos como protagonistas de suas realidades locais de saúde torna-se um investimento, à medida que garante um espírito criativo, inovador e construtivo nas ações promotoras da cidadania e transformação social, contribuindo para a eficácia, a resolutividade e o impacto social das mesmas ${ }^{18}$.

\section{CONCLUSÃO}

A intervenção educativa permitiu mostrar aos adolescentes o SUS e como eles podem contribuir na construção e consolidação do mesmo por meio da participação em saúde. Os resultados obtidos por meio da avaliação após a intervenção demonstraram respostas superiores às anteriores, indicando que a intervenção realizada potencializou e acrescentou conhecimentos em relação ao SUS aos adolescentes.

Espera-se que a partir dos conhecimentos adquiridos os adolescentes possam procurar seus conselhos 
locais e municipal de saúde e utilizar de fato do conselho social que lhes é de direito.

Entretanto, faz-se necessário reconhecer que este estudo apresenta limitações uma vez que o número de adolescentes foi bem reduzido em relação à população existente desta faixa etária no país, muito embora as reflexões proporcionadas no "ParticipAdolec" tenham girado em torno da sensibilização destes adolescentes de modo que eles sejam multiplicadores nos espaços em que estão inseridos.

Sugere-se assim que novos estudos sejam proporcionados a partir de novas estratégias que possam promover a participação dos adolescentes no SUS, bem como que os espaços de formação se tornem sensíveis para essa necessidade de envolver mais os adolescentes nos assuntos de saúde para fortalecer o sistema.

\section{REFERÊNCIAS}

1. Síntese de indicadores sociais: uma análise das condições de vida da população brasileira: 2015 / IBGE, Coordenação de População e Indicadores Sociais. Rio de Janeiro: IBGE, 2015: 137.

2. Projeção da população do Brasil por sexo e idade para o período 2000-2060; Projeção da população das unidades da federação por sexo e idade 20002030. Rio de Janeiro: IBGE, 2013.

3. Brasil. Secretaria de Atenção à Saúde. Área de Saúde do Adolescente e do Jovem. Política nacional de atenção integral à saúde de adolescentes e jovens. Brasília: Ministério da Saúde, 2007.

4. Brasil. Lei n. 12.852, de 5 de agosto de 2013. Institui o estatuto da juventude e dispõe sobre os direitos dos jovens, os princípios e diretrizes das políticas públicas de juventude e o sistema nacional de juventude - Sinajuve. Diário Oficial da União, Brasília, 2013; 1: 1-4.

5. Branco VMC, Cromack LMF, Edmundo KMB, Borges EGS, Santos LRP, Sales RP et al. Caminhos para a institucionalização do protagonismo juvenil na SMS-Rio: dos adolescentros ao RAP da Saúde. Adolesc. Saúde 201512 (1): 14-22.

6. Rabin MLR, Bacich L. O protagonismo juvenil na era digital. Revista Juventude e Políticas Públicas, Brasí- lia, 2018; 2(Edição Especial): 40-54; abr.

7. Brasil. Ministério da Saúde. Secretaria de Atenção à Saúde. Área de Saúde do Adolescente e do Jovem. Marco legal: saúde, um direito de adolescentes. Brasília: Ministério da Saúde, 2005.

8. Pons MED, Sobrinho JCS, Remedi JMR. As tecnologias da informação e comunicação e a educação à distância. REGET 2013;13(13): 2661-9.

9. Brasil. Ministério da Educação. Instituto Nacional do Desenvolvimento da Educação. Manual do aplicador do estudo CAP. Brasília. Ministério da Educação; 2002.

10. Amdocs. Amdocs survey: Teenagers have a digital lifestyle that service providers should adjust to. Disponível em https://www.amdocs.com/media-room/ amdocs-survey-teenagers-have-digital-lifestyle-service-providers-should-adjust. Acesso em: 30 ago. 2018.

11. Oliveira RNG, Gessner R, Souza V, Fonseca RMGS. Limites e possibilidades de um jogo online para a construção de conhecimento de adolescentes sobre sexualidade. Ciência \& Saúde Coletiva, 2016; 21(8): 2383-92.

12. Dias FAO, Silva MAS. O uso das ferramentas na educação a distância e o papel do tutor. Simpósio Internacional de Educação a Distância. 8 a 27 de setembro. 2016.

13. Baia RSM, Vasconcelos EV, Silva SED, Freitas KO, Gonçalves LHT. Moodle no processo educacional de enfermagem: avaliação na perspectiva do alunado. Enferm. Foco 2017;8 2):31-5.

14. Quaglia I, Oliveira A, Velho APM. Capacitação em saúde na educação a distância (ead): uma análise sistemática do conteúdo. Saúde e Pesquisa 2015;8: 103-12.

15. Brasil. Lei ${ }^{\circ} 8142 / 90$, de 28 de dezembro de 1990. Dispõe sobre a participação da comunidade na gestão do Sistema Único de Saúde (SUS) e sobre as transferências intergovernamentais de recursos financeiros na área da saúde e dá outras providências. Brasília; 1990.

16. Pereira MA. A construção da educação ambiental a partir do protagonismo juvenil em um grêmio ambiental. Ciência em tela. 2016;9(2). 
17. Sicari AS, Pereira ER. Juventude e promoção da saúde: construindo diálogos de pesquisa-intervenção. Rev Eletrônica Extensão \& Sociedade. 2015;6(2).

18. Conserva AM, Taveira FMF, Gomes LM, Marinho PS, Silva RSP. Participação social na construção do SUS: uma análise à luz da experiência brasileira. Cad. Ibero-Amer. Dir. Sanit. 2014;3 2): 102-9.

Recebido em: 12/08/2018

Aceito em: 09/10/2018 